\title{
An Economic-technical Method of Calculating Power Grid Reliability Improvement Scheme
}

\author{
Jiefu Lia*, Peng Xin, Zhongfeng Kan, Zhenxin Li, Donglin Li, Bo Jiang, Xuerui Zheng \\ State Grid Jilin Electric Power Co., Ltd. Jilin Power Supply Company, Jilin 132000, China
}

\begin{abstract}
A program to enhance the economic \& technical grid reliability is proposed in the light of improving grid reliability, The economic model of power grid upgrade program is built up. The solutions to optimize efficiency are presented step by step based on the estimated investment program \& minimum portfolio optimization program. Taking the real data of certain power supply company as example, the proposed method is proved to have certain practical value.
\end{abstract}

Keywords: power; grid reliability; economic benefits; investment estimate.

\section{Introduction}

In order to reduce the losses caused to users by distribution network failures, many researchers are actively expanding research in various aspects. The literature[1] puts forward a statistical index system of power supply reliability for users of low-voltage power distribution systems in our country, defines the meanings and calculation formulas of each index, determines the statistical boundary conditions, and proposes a lowvoltage power distribution system reliability prediction method based on artificial neural network algorithms, using the past results of the reliability statistics of power supply users and the basic data of the power grid as the training samples of the neural network to predict the future reliability of the system[2]. The distribution transformer monitoring system given in the literature [3] can accurately record the start and stop time, cumulative time and number of power outages, count the voltage qualification rate, line loss rate and power supply reliability rate, provide necessary data for comprehensive assessment of power supply quality. This distribution monitoring system can realize the calculation and comprehensive management of the reliability index of the distribution network. It improves the management level of the reliability of the power supply system, and provides a scientific basis for the decision-making of the management.

Many studies have laid a solid foundation for the improvement of power supply reliability of the distribution network and provided a theoretical basis for management decision-making. But while the reliability of power supply is improving, there are few practical economic and technical methods. Therefore, based on recent years of experience in distribution network management, this paper constructs a model of the technical and economic improvement plan, and discusses the technical and economic efficiency of the improvement plan in three parts, which can provide a theoretical basis for improving the reliability of urban distribution network power supply and future work. Fully meet the power supply needs of users, and provide users with a more abundant, continuous, safe and reliable power supply.

\section{Constructing the Economic Model of the Power Grid Promotion Scheme}

The economic model of the power grid upgrading plan is mainly composed of three parts: input volume, data analysis, and benefit and investment optimization. The flowchart is shown in Figure 1.

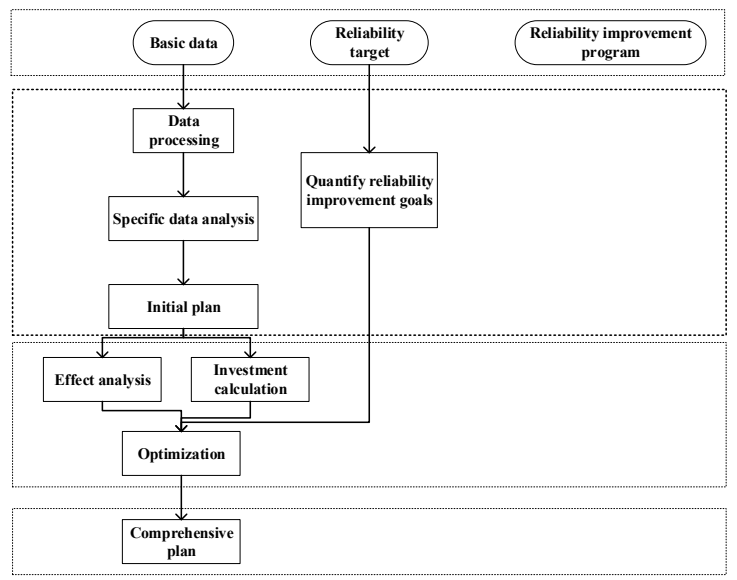

Fig.1 Economic model of power grid upgrading scheme

\footnotetext{
*Corresponding author: 13051381788@163.com
} 


\subsection{Determination of the initial plan}

In actual operation, various factors such as the structure of the distribution network's grid structure, equipment configuration, equipment technology and management level may reduce the reliability and affect the power consumption of users [4][5]. In terms of distribution network construction, maintenance, operation and management, the main consideration is to adopt five methods to improve the reliability of power supply by equipment transformation, grid optimization, management improvement, introduction of new technologies, and improvement of power supply capacity [6][7].

\subsection{Scheme optimization based on benefit and investment estimation}

Comprehensive consideration of benefits and investment, with the goal of improving reliability, so that business decisions can be optimally solved [8]. According to the actual situation of the distribution network operation and operating company, based on the preliminary plan, construct the mathematical model of investment calculation and benefit analysis, as follows.

The general unit investment benefit mathematical model of each scheme :

$$
\begin{gathered}
r=S H / C_{T} \\
C_{T}=Z_{J} L_{\text {exposed }}
\end{gathered}
$$

Where: $\quad S H$ is the number of households per year can be reduced by replacing old equipment; $C_{T}$ is the total investment; $r$ is the unit investment effect.

\subsection{Optimized strategy for power grid improvement plan}

In order to select the optimal solution, under the established target reliability requirements, the investment amount of the solution portfolio is minimized, that is, in the case of the target reliability improvement $T$, the smallest investment portfolio $P_{\min }$ is sought, and the reliability improvement program portfolio at this time It is the best solution. Its mathematical expression is:

$$
\begin{gathered}
T=F_{a} P_{a}+F_{b} P_{b}+F_{c} P_{c}+5 \\
P=P_{a}+P_{b}+P_{c}+5
\end{gathered}
$$

Where: $T$ is the number of households that need to be reduced to meet reliability requirements; $P$ series is investment; $F$ is the number of households when unit investment reliability is improved.

The analysis strategy of the reliability improvement optimization plan is:

(1) Find the value of $Q F$ the unit investment effect of each reliability improvement plan ( $Q$ is the weight of the reliability improvement plan determined by the company's current business strategy, which is discussed by relevant experts), and rank it from high to low. The higher the $Q F$, the better the investment effect of the reliability program under consideration of the current company's business strategy.
(2) Calculate the optimal scheme combination for reliability improvement under the condition that the target $\mathrm{T}$ is satisfied. If the upper limit of the number of households that can be reduced is $T \max 1>T$, then plan (1) is the optimal plan; if $T \max 1+T \max 2>T$, plan (1) + plan (2) is the optimal plan; plan (1) + plan (2) + Plan $\mathrm{N}$, if $T$ max $1+T$ max $2+T \max N>T$, plan (1) + plan (2) is the optimal plan.

(3) The investment required to calculate the optimal combination plan is $P=P_{a}+P_{b}+\ldots$

In this way, the optimal plan for the company's business decision-making can be obtained.

Linking the model with the company's actual database and combining with local actual conditions can quickly determine the optimal power supply reliability plan and improve the work efficiency of relevant personnel. The model can be applied to the operation and management of various regions.

\section{Case Analysis}

The reliability of power supply in a power supply area in Jilin province in 2019 was $99.9416 \%$, the average annual outage time for users was about $0.1169 \mathrm{~h} /$ household, and the average annual scheduled outage time was 4.9991 $\mathrm{h} /$ household. Investigate and count specific user reliability indicators, as shown in Table 1.

In Table 1, the power supply can consider RS-1 as the proportion of the total non-outage time statistics; the power supply reliability rate RS-2 is the statistical nonoutage time proportions without external influence; the electricity reliability rate RS-3 is the statistical non-outage time proportions Percentage of non-outage time; the average user outage time (AIHC-1) is the average number of outage hours of the user during the statistical period; the average user outage time (AIHC-2) is the average outage time of the user during the statistical period if external influences are not taken into account The number of hours; the average user outage time (AIHC-3) is the average number of outage hours of the user during the statistical period if the system is insufficiently powered and the power is restricted; the average outage time of the user outage ICATI- 1 is the average outage of the user during the statistical period Hours; Average number of power outages for users (AITC-1) is the average number of power outages for users during the statistical period; Average number of power outages for users (ICAIT-1) is the average number of power outages for users during the statistical period; Average number of power outages for users during the statistical period. The number of times (AFTC) is the average number of outages of the user during the statistical period. 
Table 1. Statistics Table of Reliability Indexes of Power Supply by Users.

\begin{tabular}{|c|c|}
\hline Reliability index & $\begin{array}{c}\text { Statistical } \\
\text { data }\end{array}$ \\
\hline Power supply reliability rate $(\mathrm{RS}-1) / \%$ & 99.9416 \\
\hline Power supply reliability rate (RS-2)/\% & 99.9419 \\
\hline Power supply reliability rate $(\mathrm{RS}-3) / \%$ & 99.9416 \\
\hline $\begin{array}{l}\text { Average user outage time (AIHC-1)/ } \\
\left(\mathrm{h} \cdot \text { household }^{-1}\right)\end{array}$ & 5.116 \\
\hline $\begin{array}{l}\text { Average user outage time (AIHC-2) / } \\
\left(\mathrm{h} \cdot \text { household }^{-1}\right)\end{array}$ & 5.0925 \\
\hline $\begin{array}{l}\text { Average user outage time (AIHC-3) / } \\
\left(\mathrm{h} \cdot \text { household }^{-1}\right)\end{array}$ & 5.116 \\
\hline $\begin{array}{l}\text { Average power outage time of outage } \\
\text { users }\left(\text { ICATI-1) / }\left(\mathrm{h} \cdot \text { household }^{-1}\right)\right.\end{array}$ & 7.7234 \\
\hline $\begin{array}{l}\text { Average number of power outages by } \\
\left.\text { users (AITC-1) / (times } \cdot \text { household }{ }^{-1}\right)\end{array}$ & 1.0523 \\
\hline $\begin{array}{c}\text { Average number of power outages for } \\
\text { outage users (ICAIT-1) } / \\
(\text { times } \cdot \text { household } \\
\text { (1) }\end{array}$ & 1.5886 \\
\hline $\begin{array}{l}\text { Average number of power failures for } \\
\text { users (AFTC-1) / (times } \cdot \text { household }^{-1} \text { ) }\end{array}$ & 0.062 \\
\hline
\end{tabular}

Applying the economic model of the power grid improvement scheme, calling the mathematical model of benefit and investment estimation, the calculation can obtain the technical and economic indicators of each reliability improvement scheme, as shown in Table 2 . According to the strategy weight assigned by experts, analyse and calculate the optimal plan.

Table 2. Optimized investment plan investment amount and effect.

\begin{tabular}{|c|c|c|c|c|c|c|}
\hline $\begin{array}{l}\text { Pl } \\
\text { an } \\
\text { co } \\
\text { de }\end{array}$ & $\begin{array}{c}\text { Unit } \\
\text { invest } \\
\text { ment } \\
\text { effect } \\
(\text { h·hou } \\
\text { sehold } \\
/ 10,00 \\
0 \\
\text { yuan) }\end{array}$ & $\begin{array}{l}\text { Busi } \\
\text { ness } \\
\text { strat } \\
\text { egy } \\
\text { wei } \\
\text { ght }\end{array}$ & $\begin{array}{c}\text { Unit } \\
\text { invest } \\
\text { ment } \\
\text { effect } \\
\text { consid } \\
\text { ering } \\
\text { the } \\
\text { strateg } \\
\text { y } \\
\text { (h·hou } \\
\text { sehold } \\
/ 10,00 \\
0 \\
\text { yuan) }\end{array}$ & $\begin{array}{l}\text { Lower } \\
\text { limit of } \\
\text { the } \\
\text { numbe } \\
\mathrm{r} \text { of } \\
\mathrm{h} \cdot \text { hous } \\
\text { ehold } \\
\text { (h·hou } \\
\text { sehold) }\end{array}$ & $\begin{array}{l}\text { Increas } \\
\text { ed } \\
\text { reliabil } \\
\text { ity } \\
\text { (h·hou } \\
\text { sehold) }\end{array}$ & $\begin{array}{c}\text { Inves } \\
\text { tment } \\
\text { amou } \\
\text { nt } \\
(10,0 \\
00 \\
\text { yuan })\end{array}$ \\
\hline $\mathrm{E}$ & 98.37 & 0.05 & 4.92 & 1967 & 1967 & 20 \\
\hline $\mathrm{H}$ & 40.27 & 0.05 & 2.01 & 805 & 805 & 20 \\
\hline $\mathrm{C}$ & 7.49 & 0.2 & 1.50 & 7907 & 7907 & 1056 \\
\hline $\mathrm{F}$ & 18.40 & 0.05 & 0.92 & 920 & 920 & 50 \\
\hline $\mathrm{J}$ & 4.07 & 0.05 & 0.20 & 1980 & 1980 & 486 \\
\hline $\mathrm{G}$ & 2.68 & 0.05 & 0.13 & 4878 & 2557 & 954 \\
\hline I & 0.47 & 0.05 & 0.02 & 684 & 0 & 0 \\
\hline $\mathrm{D}$ & 0.05 & 0.2 & 0.01 & 114 & 0 & 0 \\
\hline $\mathrm{A}$ & 0.002 & 0.2 & 0.0003 & 102 & 0 & 0 \\
\hline $\mathrm{B}$ & 0.00 & 0.1 & 0.00 & 0 & 0 & 0 \\
\hline
\end{tabular}

The scale and effect of each program are:

Plan E: Optimize the power outage plan, invest about 200,000 yuan, and reduce the total number of households during power outage by $5 \%$.
Plan H: Strengthen the management of power transfer, invest about 200,000 yuan, and increase the proportion of power transfer by $2 \%$.

Plan C: The overhead line adds section and branch switches, and 264 pole-mounted circuit breakers are added. The investment is about 10.56 million yuan, and the average number of households per section is reduced to 6 households/section.

Plan F: Strengthen maintenance and inspection work, invest about 500,000 yuan, and reduce the number of households caused by power failure by $5 \%$.

Plan J: Provide temporary power supply for generator vehicles, and increase the investment of generator vehicles by about 4.86 million yuan.

Plan G: Strengthen users' live connection operation, invest about 9.54 million yuan, and increase the target live operation rate to $47 \%$.

The analysis draws the following conclusions:

(1) Calculate the reliability improvement target. The reliability target of a power supply company in the State Grid Corporation of China is $99.965 \%$. In order to achieve the reliability target, compared with the current reliability level, the number of households that needs to be reduced is $16136(\mathrm{~h} \cdot$ households $) / \mathrm{a}$.

(2) Optimized combination plan for reliability improvement. The total upper limit value that can be improved for the 10 schemes is 28000 ( $\mathrm{h} \cdot$ households)/a. After sorting according to the reliability improvement effect considering the operating weight, 6 reliability improvement schemes are selected.

The optimized combination plan can reduce the number of households per hour by $16136 \mathrm{~h} /$ household. At this time, the investment amount is 25.86 million yuan (plan $\mathrm{E}+$ plan $\mathrm{H}+$ plan $\mathrm{c}+$ plan $\mathrm{F}+$ plan $\mathrm{J}+$ plan $\mathrm{G}$ ), and the reliability index is $99.965 \%$ equal to the target The value is $99.965 \%$, reaching the reliability target.

\section{Conclusion}

Based on the experience of the distribution network, an economic model of the power grid upgrading scheme was constructed. This model completes the economic and technical calculation of the reliability improvement plan of the entire power grid from the input of basic data, benefit analysis, and determination of the minimum investment optimal combination plan. Considering the actual operation of the distribution network, the scheme type and scheme name are given, and the preliminary scheme of the reliability of the distribution network is determined based on this. According to the mathematical model of investment benefit and investment estimation, the preliminary plan is analyzed for benefit and investment, and comprehensive consideration is combined with the reliability improvement target. In the case of reliability improvement goals, the smallest investment portfolio is the goal to optimize the final improvement plan. According to the actual data of a certain company, calculation and analysis, the model makes the reliability reach the target value, and the plan is optimized, indicating that the model has certain practical value. 


\section{Acknowledgments}

This work was supported by State Grid Jilin Electric Power Co., Ltd 2021-10.

\section{References}

1. Cheng F. M. (2007) Research on Power Supply Reliability Calculation and Online Monitoring of Distribution Network.: Zhengzhou University.

2. Li P. Wu J. W., Zhang Z. H., Liu S. M. \& Shi H. W. (2015) Design of static synchronous compensator for distribution network based on dual DSP structure. High Voltage Apparatus, 51, 28-33.

3. Wei R. 2013. Evaluation and prediction of power supply reliability for users of low-voltage power distribution system.: Shanghai Jiaotong University.

4. He Y. Q, Liu D. G, Zeng C \& Wen M. (2011) Distribution network reconfiguration model and its staged algorithm considering reliability. Automation of Electric Power Systems, 35, 56-60.

5. Wei J., Lu L., Wei Z. B., Liu Y. B., Gong Hui \& Cui Wei (2013) Distribution network multi-objective reconfiguration algorithm considering reliability factors. Power System Protection and Control, 41, $71-75$

6. Wu S. M., Cai X. W. \& Wang H. L. (2014) Distribution network planning method and practical application for power supply reliability. Journal of Electric Power System and Automation, 26, 70-75.

7. Zhou J. Q., Wang Z. D., Zhang D. H., Sun F. \& Feng S. (2012) Practical method of distribution network planning based on key measures to improve reliability. Power Supply, 29, 34-38+43.

8. Wang S. F., Zhang Y. J., Ren Q. \& Zhang Y. 2008. A review of quantitative analysis of distribution network reliability. Relay, 79-83. 